\title{
Lung function, hypoxic and hypercapnic ventilatory responses, and respiratory muscle strength in normal subjects taking oral theophylline
}

\author{
Shahrokh Javaheri, Luis Guerra
}

\begin{abstract}
Methylxanthines are known to be respiratory stimulants and are thought by some to augment hypercapnic and hypoxic ventilatory drive and improve respiratory muscle strength. Hypoxic and hypercapnic ventilatory responses were measured in 10 normal subjects before, during, and after administration of theophylline for three and a half days. Pulmonary function, carbon dioxide production, and mouth pressures during maximal static inspiratory and expiratory efforts were also measured. The mean (SD) serum theophylline concentration was $13.8 \quad(3.2) \mathrm{mg} / \mathrm{l}$. Lung volumes and flow rates did not change significantly with theophylline. The mean (SD) values for maximum static inspiratory pressure were 152 (27), 161 (25), and 160 (24) $\mathrm{cm} \mathrm{H}_{2} \mathrm{O}$, respectively before, during, and after theophylline. Neither these values nor peak expiratory pressure measurements were significantly changed. The slopes of the hypercapnic ventilatory responses were 2.9 $(0.9), 3.3(1 \cdot 2)$, and $3.3(1.4) 1 / \mathrm{min} / \mathrm{mm} \mathrm{Hg}$ carbon dioxide tension $\left(\mathrm{PCO}_{2}\right)$ respectively before, during, and after theophylline administration. The respective values for the slopes of the hypoxic response were $-1.4(0.9),-1.3(0.8)$, and $-1.1 \quad(0.9) \quad 1 / \mathrm{min} / 1 \%$ oxyhaemoglobin saturation. None of these values changed significantly with theophylline. Theophylline, however, increased carbon dioxide production (200 to $236 \mathrm{ml} / \mathrm{min}$ ) and alveolar ventilation ( 4.7 to $5 \cdot 71 / \mathrm{min})$ significantly, with a concomitant fall of end tidal $\mathrm{PCO}_{2}(35.5$ to $32.9 \mathrm{~mm} \mathrm{Hg})$. It is concluded that in man oral theophylline at therapeutic blood concentrations increases carbon dioxide production and ventilation without changing pulmonary function, respiratory muscle strength, or the hypoxic or hypercapnic ventilatory response significantly.
\end{abstract}

Methylxanthines are respiratory stimulants, ${ }^{1}$ and have been used as such to treat infants ${ }^{2}$ and adults ${ }^{3}$ with central apnoea and CheyneStokes respiration ${ }^{45}$ successfully for 50 years.

Address for reprint requests: Dr S Javaheri, Veterans Affairs Medical Center, Pulmonary Section, 3200 45220, USA

Accepted 4 April 1990
The mechanisms by which theophylline mediates the improvement in ventilation are not clear; augmentation of hypoxic and hypercapnic ventilatory responses has, however, been suggested. ${ }^{1}$

Several studies have looked at the effects of theophylline on the ventilatory response to hypoxia and hypercapnia in man, ${ }^{6-10}$ though in some, ${ }^{810}$ in which theophylline augmented hypercapnic ventilatory response or diminished carbon dioxide retention after oxygen breathing, the studies were performed in patients with chronic obstructive lung disease in whom theophylline caused bronchodilatation. The increase in hypercapnic response might therefore have been due to the decrease in airways resistance rather than a change in chemosensitivity to carbon dioxide. ${ }^{112}$

Only three systematic studies to our knowledge have been concerned with the ventilatory effects of theophylline in normal man. ${ }^{679}$ Stroud and associates ${ }^{9}$ showed that intravenous administration of aminophylline ( 3 and $6 \mathrm{mg} / \mathrm{kg}$ ) in man displaced the ventilation carbon dioxide curve (measured by a steady state technique) upward and to the left (to a higher ventilation for a given expired carbon dioxide concentration). In contrast, Lakshminarayan and colleagues ${ }^{6}$ reported that intravenous administration of $5 \mathrm{mg} / \mathrm{kg}$ of aminophylline had no significant effect on the slope or intercept of hypercapnic response in six normal subjects but significantly augmented the response to hypoxia measured at the prevailing carbon dioxide tension $\left(\mathrm{PCO}_{2}\right)$. In the study of Sanders and associates, ${ }^{7}$ however, aminophylline did not augment the ventilatory response to hypoxia when measurements were performed at the prevailing $\mathrm{PCO}_{2}$ (which was lower in those given aminophylline than in the control subjects). Aminophylline rather than theophylline was used in all these studies, most were performed after intravenous administration, and the number of subjects studied was usually small.

In this study we report the effects of maintained treatment with oral theophylline on lung function, hypoxic and hypercapnic ventilatory responses, and respiratory muscle strength in 10 normal subjects. Because subjects usually recognise theophylline, a double blind approach is difficult, so we performed measurements before, during, and after administration of theophylline.

Our specific aim was to investigate whether 
oral theophylline increases ventilatory responses, and if so whether the augmentation is due to bronchodilatation, to an increase in respiratory muscle strength, or to a rise in metabolic rate.

\section{Methods}

We studied 10 healthy non-smoking men aged 22-39 years. All were medical personnel but unaware of the reason for the experiment. The protocol was approved by the Institutional Review Board at the University of Cincinnati College of Medicine.

TESTS

Spirometric and ventilatory measurements and tests of muscle'strength were carried out before the drug trial and served as a training run. Tests were performed two hours after a meal and at the same time of day for each subject. All subjects refrained from beverages containing caffeine derivatives on the day of the study.

Details of the techniques used for the pulmonary function tests in our laboratory have been published. ${ }^{14}$ Spirometric tests were performed in triplicate (Collins/DS, W E Collins, Braintree, Montana) and the highest value was used. Transfer factor for carbon monoxide (TLCO) was determined by the single breath technique, and functional residual capacity (FRC) by helium rebreathing.

The ventilatory tests were measured with the subject sitting, wearing a nose clip and breathing through a mouthpiece connected to a low resistance two way valve (Hans-Rudolph, Kansas City, Missouri). Auditory distraction was provided by radio headphones. Inspiratory flow and volume were measured by a pneumoscan S-301 spirometer (KL Engineering, Sylmar, California), calibrations were performed on the basis of using known flow rates from a pneumatic calibrator (Model 65-250, Pennwalt Corporation, Belleville, New Jersey) and 3 litre syringes for volume. End tidal carbon dioxide was sampled at the mouthpiece by an infrared carbon dioxide analyser (Beckman Medical Gas Analyzer, LB-2, Beckman Cardiopulmonary Instruments, Fullerton, California). Arterial oxygen saturation $\left(\mathrm{SaO}_{2}\right)$ was measured by ear oximetry (BTI Biox II A, Bioximetry Technology, Boulder, Colorado).

Measurements started after achievement of a steady state as shown by a stable end tidal $\mathrm{PCO}_{2}$. Resting ventilation was measured with the subject breathing room air and a timed volume of exhaled gas was collected for calculation of carbon dioxide production $\left(\mathrm{V} \mathrm{CO}_{2}\right)$. Deadspace and alveolar ventilation were calculated from the Bohr equation and the alveolar ventilation equation on the basis of known end tidal carbon dioxide, mixed expired carbon dioxide, carbon dioxide production, and minute ventilation.

The hypercapnic ventilatory response was determined by the rebreathing method of Read..$^{15}$ Data points after the appearance of a mixed venous $\mathrm{PCO}_{2}$ plateau were used in the calculations. Linear regression was used to derive the equation $\dot{V}_{\mathbf{E}}=\mathbf{S}\left(\mathrm{PCO}_{2}-\mathrm{B}\right)$, where $S$ is the slope of response and $B$ is the intercept on the $\mathrm{PCO}_{2}$ axis. The isocapnic hypoxic ventilatory response was performed by the rebreathing method of Rebuck and Campbell. ${ }^{16}$ End tidal $\mathrm{PCO}_{2}$ was maintained at the prevailing levels by removing carbon dioxide from the circuit by two variable speed pumps connected to a carbon dioxide absorber. Rebreathing was stopped when arterial oxygen saturation reached $70 \%$. Data points from $90 \%$ to $70 \%$ saturation were used to relate ventilation to saturation by least squares regression analysis. A minimum of 10 minutes was allowed between each test.

Respiratory muscle strength was assessed by measuring mouth pressures during maximal static inspiratory (PIPmax) and expiratory (PEPmax) efforts against an obstructed mouthpiece with a small leak to minimise oral pressure artifacts. ${ }^{1617}$ The pressures were measured at residual volume (PIPmax) and at total lung capacity (PEPmax), maintained for one second and determined three to five times until at least two technically satisfactory measurements were recorded.

Theophylline serum concentration was determined with the Kodak Ektachem 700 (Rochester, New York).

\section{EXPERIMENTAL DESIGN}

Training studies were performed two days before baseline measurements, to acquaint subjects with the laboratory and equipment and minimise their anxiety, and to enable them to practise PIP and PEP manoeuvres. Baseline measurements (run I) were performed the day before subjects were given sustained release theophylline (Theo-Dur, Key Pharmaceutical, Kenilworth, New Jersey), $10 \mathrm{mg} / \mathrm{kg} /$ day in two divided doses (every 12 hours), by mouth. Measurements were repeated (run II) on the fourth day and a venous blood sample obtained for determination of theophylline concentration. A third set of measurements (run III) was obtained at least two weeks after theophylline administration had been stopped.

\section{STATISTICAL ANALYSIS}

Slopes of ventilatory responses were calculated without knowledge of drug treatment. Statistical significance was determined by analysis of variance with repeated measures and multiple paired $t$ tests. The Bonferroni correction factor was used when more than two variables were compared. The SAS computer system, University of Cincinnati, was used for calculations. Data are presented as means with standard deviations in parentheses. Values of $p$ below 0.025 were considered significant.

\section{Results}

The mean (SD) age was $31 \cdot 2(5 \cdot 4)$ years, height $176(7) \mathrm{cm}$, and body weight 78 (15) $\mathrm{kg}$. The mean serum theophylline concentration was $13.8(3.2)$ (range $7 \cdot 4-17 \cdot 8$ ) $\mathrm{mg} / \mathrm{l}$ during the second study; eight subjects had concentrations above $12 \mathrm{mg} / \mathrm{l}$.

Mean baseline FRC total lung capacity (TLC), and TLCo were 2.82 (0.87), 6.54 (0.77), $1.38(0.46) \mathrm{l}$, and $35.0(3.0) \mathrm{ml} / \mathrm{min} / \mathrm{mm} \mathrm{Hg}$. 
Ventilation and gas exchange (mean (SD) values) before, during, and after theophylline administration

\begin{tabular}{|c|c|c|c|c|c|c|c|}
\hline Run $\dagger$ & $\begin{array}{l}R R \\
(/ \min )\end{array}$ & $\begin{array}{l}V T \\
(m l)\end{array}$ & $\begin{array}{l}\dot{V}_{E} \\
(l / \min )\end{array}$ & $\begin{array}{l}\dot{V} \mathrm{CO}_{2} \\
(\mathrm{ml} / \mathrm{min})\end{array}$ & $\begin{array}{l}\dot{V}_{A} \\
(l / \min )\end{array}$ & $\begin{array}{l}\dot{V}_{D} \\
(l / \min )\end{array}$ & $\begin{array}{l}\mathrm{PECO}_{2} \\
(\mathrm{~mm} \mathrm{Hg})\end{array}$ \\
\hline $\begin{array}{l}\text { I } \\
\text { II } \\
\text { III }\end{array}$ & $\begin{array}{l}12 \cdot 4(4 \cdot 2) \\
14 \cdot 0(4 \cdot 7) \\
13 \cdot 4(2 \cdot 4)\end{array}$ & $\begin{array}{l}676(162) \\
718(129) \\
619(128)\end{array}$ & $\begin{array}{l}8.00(2 \cdot 11) \\
9.63 \ddagger(2 \cdot 23) \\
8.29(2 \cdot 09)\end{array}$ & $\begin{array}{l}200(59) \\
236 \ddagger(50) \\
207(57)\end{array}$ & $\begin{array}{l}4 \cdot 72(1 \cdot 50) \\
5 \cdot 77 \ddagger(1 \cdot 19) \\
4 \cdot 77(1 \cdot 24)\end{array}$ & $\begin{array}{l}3.28(0.95) \\
3.88(1.15) \\
3.52(0.80)\end{array}$ & $\begin{array}{l}35.5(2.3) \\
32.9 \ddagger(2.5) \\
35.0(2.0)\end{array}$ \\
\hline
\end{tabular}

$\star \dot{\mathrm{V}} \mathrm{CO}_{2}$ is at STPD and the other measurements at BTPS.

$\dagger \mathrm{I}-$ before theophylline; II - on theophylline; III-after theophylline.

†p $<0.025 v$ baseline value.

$\mathrm{RR}$-respiratory rate; $\mathrm{VT}$-tidal volume; $\dot{\mathrm{V}}$-minute ventilation; $\dot{\mathrm{V}} \mathrm{CO}_{2}$-carbon dioxide production; $\dot{\mathrm{V}} \mathrm{A}$-alveolar ventilation; $\mathrm{V}_{\mathrm{D}}$-deadspace ventilation; $\mathrm{PECO}_{2} \longrightarrow$ end tidal carbon dioxide tension.

Mean baseline values for forced vital capacity (FVC), $\mathrm{FEV}_{1}, \mathrm{FEV}_{1} / \mathrm{FVC}$, peak expiratory flow (PEF), and peak inspiratory flow (PIF) were $5.04(0.42) 1,4.36(0.54) 1,86 \%(5 \%)$, $12.5(1.5) 1 / \mathrm{s}$, and $9.1(1.3) \mathrm{l} / \mathrm{s}$. There were no significant changes in any of these measurements during the study.

Mean PIP was 152 (27), 161 (25), and 160 (24) $\mathrm{cm} \mathrm{H}_{2} \mathrm{O}$ for runs I, II, and III. The corresponding values for PEP were 227 (17), 234 (27), and 231 (31) $\mathrm{cm} \mathrm{H}_{2} \mathrm{O}$. The maximum difference between the mean value of the best and the next best value for a given measurement was $3.8 \%$, indicating good reproducibility. Theophylline had no significant effect on either PIPmax or PEPmax.

Carbon dioxide production, minute ventilation, and alveolar ventilation increased significantly with theophylline and end tidal carbon dioxide tension $\left(\mathrm{PECO}_{2}\right)$ fell significantly (table). These variables returned to baseline values after theophylline had been stopped.

Mean values for $S$ of the ventilatory response and the intercept of the response did not change significantly with theophylline administration. For the hypercapnic responses the mean values of B ( $x$-intercept) were $39.5(2 \cdot 6), 38 \cdot 7(2 \cdot 9)$, and $40.9(3.1) \mathrm{mm} \mathrm{Hg}$ for runs I, II, and III. The corresponding $S$ values were $2 \cdot 9(0.9), 3 \cdot 3$ $(1 \cdot 2)$, and $3.3(1.4) 1 / \mathrm{min} / \mathrm{mm} \mathrm{Hg} \mathrm{PcO}$. Ventilation for runs I, II, and III at a $\mathrm{PCO}_{2}$ of $60 \mathrm{~mm} \mathrm{Hg}$ was $59.9(20.9), 71.4(26.8)$, and $62.3(25 \cdot 5) 1 / \mathrm{min}$ and did not differ significantly. The $S$ values for the hypoxic response were $-1.4(0.9),-1.3(0.8)$, and $-1.1(0.9) 1 /$ $\mathrm{min} / 1 \%$ oxyhaemoglobin saturation for runs $\mathrm{I}$, II, and III. There were no significant correlations between serum theophylline concentrations and the $S$ values of ventilatory response or their respective changes from baseline.

We attempted to standardise the ventilatory responses. During the hypoxic test the mean time spent between $90 \%$ and $70 \%$ oxyhaemoglobin saturation did not differ significantly (169 (22), 154 (34), and 158 (30) seconds for runs I, II, and III). Mean $\mathrm{PECO}_{2}$ values during the three hypoxic response measurements were also similar $(34.9(2 \cdot 0)$. $33.7(2 \cdot 5), 34.9(1 \cdot 7) \mathrm{mm} \mathrm{Hg})$.

\section{Discussion}

From this study in normal man we draw four main conclusions. Theophylline at therapeutic plasma concentrations increases carbon dioxide production and alveolar ventilation and decreases end tidal $\mathrm{PCO}_{2}$; theophylline does not significantly change lung volumes or flow rates (thus confirming the results of Estenne et $a l^{18}$ ); theophylline does not significantly affect inspiratory or expiratory muscle strength; and, importantly, it does not significantly change the slopes or intercepts of hypoxic and hypercapnic ventilatory responses.

\section{THEOPHYLLINE AND MUSCLE STRENGTH}

Care was taken in measuring inspiratory and expiratory muscle strength, and subjects were trained to carry out the manoeuvre. Measurements were reproducible, as the closeness of the mean values of the two highest observations showed. The lung volumes at which PEPmax and PIPmax were performed (TLC and RV) remained virtually unchanged.

Our results strongly suggest, therefore, that in normal man oral theophylline does not improve respiratory muscle strength as measured by this technique. These data are consistent with the findings of Moxham et al, ${ }^{19}$ who showed that theophylline had no effect on diaphragmatic contractility evoked by percutaneous phrenic nerve stimulation. Similar results were reported for the sternomastoid muscle. ${ }^{20}$ The results differ, however, from those obtained by Murciano and associates in normal subjects ${ }^{21}$ and in patients with chronic obstructive lung disease. ${ }^{22} 23$ Improved inspiratory muscle contractility after theophylline in patients with chronic obstructive lung disease does not necessarily mean that theophylline has a direct effect on the diaphragm. As theophylline improves pulmonary function in these patients this might have resulted in improvement of respiratory muscle strength. $^{22}$

\section{EFFECT OF THEOPHYLLINE ON VENTILATORY RESPONSES}

Although methylxanthines are often said to augment hypoxic and hypercapnic ventilatory responses, ${ }^{1}$ theophylline had no significant effect in either test in our subjects. The lack of effect on the carbon dioxide response contrasts with the results of some earlier studies ${ }^{9}$ but is in agreement with the findings of Lakshminarayan et al $^{6}$ and Sanders et al. ${ }^{7}$ Lakshminarayan et al did, however, show an increase in the hypoxic ventilatory response with intravenous aminophylline.

Hypoxic ventilatory response may not be measuring a single factor as is commonly assumed. When man is subjected to sustained hypoxia, ventilation increases initially owing to stimulation of carotid bodies; later ventilation falls. ${ }^{24}$ Hypoxic ventilatory depression is most easily shown in anaesthetised animals with 
denervation of the carotid body. ${ }^{25}{ }^{26}$ Changes in ventilation during hypoxia may represent the algebraic sum of peripheral chemoreceptor stimulation and central ventilatory depression, the contribution of the latter depending on the degree and duration of hypoxia. Our observations in anaesthetised, spontaneously breathing animals ${ }^{26}$ and the results of Easton and Anthonisen in $\operatorname{man}^{24}$ indicate that hypoxic ventilatory depression usually takes several minutes to develop. We believe that respiratory depression is unlikely to have occurred during our hypoxic ventilatory tests, as they lasted less than three minutes. Hypoxic ventilatory depression might, however, have occurred in the study of Lakshminarayan $e t a l^{6}$ as the hypoxia lasted seven minutes; the hypoxaemia was also more severe, arterial oxygen tension $\left(\mathrm{PaO}_{2}\right)$ falling to around $30 \mathrm{~mm} \mathrm{Hg}(4.0 \mathrm{kPa})$ whereas in our study the minimum $\mathrm{PaO}_{2}$ was about $40 \mathrm{~mm} \mathrm{Hg}(5.3 \mathrm{kPa})$. If our assumption is correct and hypoxic depression occurred in the studies of Lakshminarayan and associates, the augmentation of hypoxic response by aminophylline noted in that study may have been due to reversal of the central depression. ${ }^{24-26}$ Theophylline has been shown to reduce ventilatory depression in $\operatorname{man}^{24}$ and in anaesthetised cats whether breathing spontaneously ${ }^{26}$ or paralysed and mechanically ventilated. ${ }^{25}$

\section{THEOPHYLLINE AND VENTILATION}

Our results show that oral theophylline at therapeutic plasma concentrations increases resting minute and alveolar ventilation and decreases end tital $\mathrm{PCO}_{2}$. Deadspace did not change, which is consistent with the lack of bronchodilatation with theophylline. The increase in ventilation was not associated with any significant improvement in inspiratory or expiratory muscle strength. Aubier and associates $^{27}$ found that aminophylline increased ventilation in anaesthetised dogs by improving diaphragmatic strength.

Theophylline has increased carbon dioxide production significantly in $\operatorname{man}^{6}{ }^{6 a t},{ }^{28}$ and dog. ${ }^{29}$ The rise in carbon dioxide production was in part due to the increased work of breathing (as reflected by the increase in ventilation), but is probably due mainly to an increase in metabolic rate related to a generalised potentiation of muscular contractions as a result of facilitation of neuromuscular transmission. ${ }^{30}$ Alveolar ventilation rose more than was accounted for by increased carbon dioxide production, so that $\mathrm{PECO}_{2}$ fell. A fall in $\mathrm{PCO}_{2}$ would tend to depress ventilation, so the theophylline induced augmentation of ventilation may be underestimated. Eldridge and associates $^{31}$ and Javaheri and colleagues ${ }^{32}$ showed that aminophylline increased ventilation considerably in anaesthetised cats when end tidal and arterial $\mathrm{PCO}_{2}$ were kept relatively constant.

The increase in ventilation seen with theophylline may be related to inhibition of adenosine at A-1 receptors, adenosine being inhibitory in the central nervous system and in the neuronal circuit concerned with breathing. ${ }^{2631} 32$ As theophylline increased ventilation in the present study in the absence of sig- nificant change in hypoxic and hypercapnic ventilatory responses, respiratory muscle strength, or lung function, we may reasonably suggest that in man, as in the cat, ${ }^{31}{ }^{32}$ this action is due to inhibition of adenosine, which should be tonically inhibiting ventilation. Theophylline, at therapeutic plasma concentrations, is believed to be a specific inhibitor of adenosine. ${ }^{1}$ This mechanism of action may also account for the therapeutic effect of theophylline on central apnoea and Cheyne-Stokes respiration $^{3-5}$ as adenosine is released in the brain during hypoxia. ${ }^{33}$ Further work, however, is necessary to show the relation between theophylline, adenosine, and these breathing disorders.

This research was supported in part by grants from the Department of Veterans Affairs.

1 Rall TW. Central nervous system stimulants: the methylxanthines. In: Gilman AG, Goodman LD, Rall TW, Murad F, eds. The pharmacological basis of therapeutics. 7th ed. New York: Macmillan, 1985:589-603.

2 Kelly DH, Shannon DC. Treatment of apnea and excessive periodic breathing in the full-term infant. Pediatrics 1981;68:183-6.

3 Espinoza H, Antic R, Thornton A, McEvoy R. The effects of aminophylline on sleep and sleep-disordered breathing in patients with obstructive sleep apnea syndrome. Am Rev Respir Dis 1987;136:80-4.

4 Marais OAS, McMichael J. Theophylline-ethylenediamine in Cheyne-Stokes respiration. Lancet 1937;ii:437-40.

5 Dowdell WT, Javaheri S, McGinnis W. Cheyne-Stokes respiration presenting as sleep apnea syndrome: clinical and polysomnographic features. Am Rev Respir Dis 1990;141:871-9.

6 Lakshminarayan S, Sahn SA, Weil JV. Effect of aminophylline on ventilatory responses in normal man. Am Rev Respir Dis 1978;117:33-8.

7 Sanders S, Berman T, Bartlett M, Kronenberg R. Increased hypoxic ventilatory drive due to administration of aminophylline in normal men. Chest 1980;78:279-82.

8 Galdston M, Geller J. Effects of aminophylline and diamox alone and together on respiration and acid-base balance and on respiratory response to carbon dioxide in pulmonary emphysema. Am J Med 1957;22:183-96.

9 Stroud MW, Lambertsen $\mathrm{CH}$, Ewing JH, Kovgh $\mathrm{RH}$, Gould RA, Schmidt CF. The effects of aminophylline and meperidine alone and in combination on the respiratory response to carbon dioxide inhalation. J Pharmacol Exp Ther 1955;114:461-9.

10 Galdston M, Myles MB. The use of aminophylline in respiratory depression and carbon dioxide retention induced by oxygen inhalation in patients with pulmonary emphysema. Am J Med 1962;33:852-63.

11 Javaheri S, Lucey EC, Snider GL. Premorbid ventilatory response to hypercapnia is not related to resting arterial $\mathrm{PCO}_{2}$ in hamsters with elastase-induced emphysema. $\mathrm{Am}$ Rev Respir Dis 1985;132:1055-9.

12 Javaheri $S$. Premorbid hypercapnic ventilatory response and $\mathrm{PaCO}_{2}$ in emphysema. Pflügers Archiv 1987: $408-29$.

13 Javaheri S, Bosken CH, Lim SP, Dohn MN, Greene NB, Baughman RP. Effects of hypohydration on lung functions in humans. Am Rev Respir Dis 1987;135:597-9.

14 Read DJC. A clinical method for assessing the ventilatory response to $\mathrm{CO}_{2}$. Aust Ann Med 1967;16:22-32.

15 Rebuck AS, Campbell EJM. A clinical method for assessing the ventilatory response to hypoxia. Am Rev Respir Dis the ventilatory respo

16 Rochester DF, Avora NS. Respiratory muscles failure. Med Clin North Am 1983;67:573-97.

17 Black LF, Hyatt RE. Maximal respiratory pressures: normal values and relationship to age and sex. Am Rev Respir Dis 1969;99:696-702.

18 Estenne M, Yernault JC, Troyer AD. Effects of parenteral aminophylline on lung mechanics in normal human. $\mathrm{Am}$ aminophylline on lung mechanics

19 Moxham J, Miller J, Wiles CM, Morris A, Green M. Effect of aminophylline on the human diaphragm. Thorax 1985;40:288-92.

20 Efthimiou J, Fleming J, Edwards RHT, Spiro SG. Effect of aminophylline on fatigue of the sternomastoid muscle in man. Thorax 1986;41:122-7.

21 Murciano D, Aubier M, Viires N, Mal H, Pariente R. Effects of theophylline and enprofylline on diaphragmatic contractility. J Appl Physiol 1987;63:51-7.

22 Murciano D, Aubier M, Lecocguic Y, Pariente R. Effects of 
theophylline on diaphragmatic strength and fatigue in patients with chronic obstructive pulmonary disease. $N$ Engl J Med 1984;311:349-53.

23 Murciano .D, Auclair MH, Pariente R, Aubier M. A randomized, controlled trial of theophylline in patients with severe chronic obstructive pulmonary disease. $N$ Engl J Med 1989;320:1521-5.

24 Easton PA, Anthonisen NR. Ventilatory response to sustained hypoxia after pretreatment with aminophylline. $J$ Appl Physiol 1988;64:1445-50.

25 Millhorn DE, Eldridge FL, Kiley JP, Waldrop TG. Prolonged inhibition of respiration following acute hypoxia in glomectomised cats. Respir Physiol 1984;57:331-40.

26 Javaheri S, Teppema LJ, Evers JAM. Effects of aminophylline on hypoxemia-induced ventilatory depression in cats. J Appl Physiol 1988;64:1837-43.

27 Aubier M, Murciano D, Viires N, Lecocguic Y, Palacios S, Pariente R. Increased ventilation caused by improved diaphragmatic efficiency during aminophylline infusion. Am Rev Respir Dis 1983;127:148-54.
28 Lundberg DB, Breese GR, Mueller RA. Aminophylline may stimulate respiration in rats by activation of dopaminergic receptors. J Pharmacol Exp Ther 1981;217:215-21.

29 Olsen GG, Schlitt SC. Theophylline effect upon respiration and ventilation in the dog. $J$ Pharmacol Exp Ther 1981;217:278-84.

30 Breckenridge BM, Burn JH, Matschinsky FM. Theophylline epinephrine and neostigmine facilitation of neuromuscular transmission. Proc Natl Acad Sci 1962;57:1893-7.

31 Eldridge FL, Millhorn DE, Kiley JP. Antagonism by theophylline of respiratory inhibition induced by adenosine. J Apply Physiol 1985;59:1428-33.

32 Javaheri S, Evers JAM, Teppema LJ. Increase in ventilation caused by aminophylline in the absence of changes in ventral medullary extracellular fluid $\mathrm{pH}$ and carbon dioxide tension. Thorax 1989;44:121-5.

33 Winn HR, Rubino R, Berne RM. Brain adenosine concentration during hypoxemia in rats. Am J Physiol 1981;241:H235-42. 